\title{
Are nanomaterials making agriculture more productive? outputs from a metadata analysis of 2009-2020 research
}

Eduardo Santos Rodrigues ${ }^{\mathrm{a}}$, Gabriel Sgarbiero Montanha ${ }^{\mathrm{a}}$, Marcos Henrique Feresin Gomes ${ }^{\mathrm{a}}$, Nádia Marion Duran ${ }^{a}$, Camila Graziele Corrêa ${ }^{a}$, Sara Luiza Zachi Romeu ${ }^{a}$, Anderson Espirito Santo Pereira ${ }^{\mathrm{b}}$, Jhones Luiz de Oliveira ${ }^{\mathrm{b}}$, Eduardo de Almeida ${ }^{\mathrm{a}}$, Alejandro Pérez-de-Luque ${ }^{\mathrm{c}}$, Subhasis Ghoshal ${ }^{\mathrm{d}}$, Catherine Santaella ${ }^{\mathrm{e}}$, Renata de Lima $^{\mathrm{f}}$, Leonardo Fernandes Fraceto ${ }^{\mathrm{b}}$, Hudson Wallace Pereira de Carvalho a,*

a University of São Paulo (USP), Center of Nuclear Energy in Agriculture (CENA), Laboratory of Nuclear Instrumentation, Piracicaba, 13416-000, São Paulo, Brazil.

b São Paulo State University (UNESP), Institute of Science and Technology, Sorocaba, 18087180, São Paulo, Brazil.

c IFAPA Alameda del Obispo, Area of Genomic and Biotechnology, Avenida Menéndez Pidal, S/N, 14004, Córdoba, Spain.

${ }^{\mathrm{d}}$ McGill University, Department of Civil Engineering, Montreal, Quebec, Canada H3A 0C3

e Aix Marseille Univ, CEA, CNRS, BIAM, Laboratory of Microbial Ecology of the Rhizosphere, F-13008 Saint-Paul-lès-Durance, France

${ }^{\mathrm{f}}$ University of Sorocaba (Uniso), Bioactivity Assessment and Toxicology of Nanomaterials Lab (Labiton), Sorocaba, 18023-000, São Paulo, Brazil.

*Corresponding author: Prof. Hudson Wallace Pereira de Carvalho

E-mail: hudson@cena.usp.br

Phone: $+5519+551934294737$ 


\begin{abstract}
Agriculture is responsible for supplying food, feed, fibres, and an increasing fraction of fuel and raw chemicals for industry. Fulfilling such demands sustainably is one of the major challenges of our time. In this metadata analysis of 10 years of published research, we offer a quantitative overview of how scientists have been addressing the effects of nanoparticles on plants, and which were the main findings. If one hand, cultivated crops (55\%) and plant nutrients (52\%) are mostly employed as subjects of the studies, nanoparticle concentration ranges are much above, in general, more than twice that of those supplied by fertilizers or background soil concentration. Likewise, the time span of most studies, median 49 days for plants cultivated in soil, are still short compared to crop life-cycles (90-120 days), furthermore little attention ( $12 \%$ of treatments) has been dispensed to soil microorganisms. It was not possible to establish correlations between effects and experimental parameters such as concentration range, soil $\mathrm{pH}$, or time of exposure, which reveals an intricate relationship between these results and experimental conditions. The small fraction of field experiments $(5 \%)$ is also challenging to be transposed. Finally, the study raises the question of whether nanoscience will lead to incremental yield gains by replacing current inputs by nanotechnological ones, such as the controlled-release of fertilizers and pesticides, or it will disrupt agriculture by attacking problems so far not practically addressed such as hacking plant stress and defense mechanisms, and modulation of metabolism and photosystems.
\end{abstract}




\section{Agriculture under pressure}

Agriculture is currently under a huge strain as demands for food, feed, fiber, fuel, and biomass-based molecules rise ${ }^{1,2}$. It is expected that agricultural outputs have to be increased by $70 \%$ in the next few decades ${ }^{3}$, yet shrinking farmlands make it difficult to support the demands on agriculture ${ }^{4}$.

Meeting higher agricultural yields implies overcoming many challenges, such as promoting nutrient use efficiency, soil protection, drought and salt tolerance, and the management of several harms induced by arthropods, pathogenic fungi, bacteria, and viruses, as well as parasitic weeds ${ }^{5-9}$.

In this context, how could nanotechnology contribute to the development of more sustainable and productive agriculture? In principle, many inherent properties of nanosized particles (NPs), e.g., larger contact surface, size and shape-dependent solubility, and surface charge flexibility ${ }^{10,11}$ might play crucial roles in plant nutrition, disease management, and crop production driving better protection against biotic and abiotic stresses ${ }^{12}$, enhancement of photosynthetic efficiency ${ }^{13,14}$, control of fertilizer's release ${ }^{15-17}$ and even enabling the synthesis of doped-nanodevices for 'smart'-delivery of bioactive compounds and minerals to target tissues $^{18,19}$.

The present study brings a quantitative overview of previously published studies involving inorganic nanoparticles and plants. It includes 996 peer-reviewed publications found at the Web of Science database between 2009 and 2020. The following keywords and booleans were employed: "nanomaterial OR nanoparticle OR nanotechnology" and "plant OR seed OR agriculture". Papers approaching nanoencapsulation of chemicals were not taken into account. This systematic metadata survey aimed at answering ten broad questions:

1) Which nanoparticles (NPs) have been tested?; 2) Which plant species have been exposed to NPs?; 3) What is the size range of NPs?; 4) Did the studies with plants employ any 
kind of positive control?; 5) Where have the experiments been carried out?; 6) Which plant parts or organs have been exposed to NPs; 7) How long plants have been exposed to NPs?; 8) Which was the concentration range of NPs?; 9) What was the effect of nanomaterials on soil microorganisms?

Replying to these questions may give a glimpse into how nanoparticle-plant interactions have been addressed. Additionally, it might point out whether the knowledge generated allows us to conclude on the real contribution of nanomaterials for optimized and sustainable agriculture.

Due to the variability of experimental strategies and the lack of a standardized procedure employed by the different authors, the survey here presented does not aim at making statistical analysis or extrapolation. We included papers strictly following the keywords and booleans criteria above-mentioned and no intentional bias was exerted in the selection. Further details on the criteria used to select the manuscripts are provided in the electronic supplementary information (ESI). The strategy of data mining, and the error/uncertainty estimation method are also provided in the ESI. Furthermore, the raw metadata used for the creating each figure is indexed in a Figshare reposity ${ }^{20}$ 


\section{Experimental design}

Figure 1 shows that most studies employed NPs as metal (25\%) or metal oxides (54\%), whereas $10 \%$ of the studies explored carbon-based NPs such as fullerenes, graphene, and carbon nanotubes. Among the metal oxides, $\mathrm{ZnO}, \mathrm{TiO}_{2}, \mathrm{CuO}$, and $\mathrm{CeO}_{2}$ account for more than a third of all studied NPs. Moreover, Ag appears in $12.7 \%$ of them, outstanding as the most frequently employed metallic NP.

The analyzed articles cluster NPs into four main branches: 1) Plant nutrient supply; 2) Stimulation of plant metabolism; 3) Mechanisms of NP uptake, transport, storage, and metabolism in plants; 4) Impacts and toxicity on plants. The survey captured the leading topic of interest of the scientific community, which is increasing plant productivity through nanobased fertilizers since $52 \%$ of the data entries employed plant nutrient NPs or also evaluated NP-driven crop protection. However, a noteworthy fraction of these studies were either related to toxicity and risk assessment or the evaluation of the NPs uptake, with no intent to address the practical applications of these systems later.

Another approach concerns the use of NPs made of beneficial or non-nutrient materials with stimulatory effects, e.g., enhancing germination, plant development, and antioxidant responses $^{21-25}$.

$\mathrm{ZnO}, \mathrm{TiO}_{2}, \mathrm{CeO}_{2}$, and $\mathrm{Ag}$ NPs are produced in large quantities by industry ${ }^{26}$, hence several studies aimed at evaluating whether these NPs contained in commercial goods, will eventually end up in the environment, thereby affecting plants ${ }^{27}$. One can highlight that $\mathrm{ZnO}$ and $\mathrm{TiO}_{2}$ are present in sunscreen products and cosmetics, while Ag presents antimicrobial properties and is used in antimicrobial coatings, and many textiles, keyboards, wound dressings, and biomedical devices ${ }^{28-35}$.

Plants are fundamental components of ecosystems, and due to the characteristics of absorption and bioaccumulation, they are widely used as models for these tests ${ }^{36}$. Furthermore, 
understanding the toxicity mechanisms of these NPs is an important point to better design them, either through component changes or even synthesis routes, to obtain systems with the least environmental side effects. It is worth noting that, for a redesign of these systems, an important aspect is that in addition to reducing the toxicity to non-target organisms and relevant environmental compartments, the nanomaterials must still have appropriate properties for their different applications ${ }^{37}$.

Since $\mathrm{Ag}, \mathrm{Au}, \mathrm{TiO}_{2}, \mathrm{CeO}_{2}$, and $\mathrm{Al}_{2} \mathrm{O}_{3}$ are not found in plants at appreciable concentrations, their background signals are very low, easing their detection and making them suitable for mechanistic studies investigating the uptake, transport, storage, and metabolism of NPs.

Most studies employed crop species responsible for producing staple food. Figure 2 reveals that species from Poaceae, Fabaceae, and Solanaceae families encompass more than $55 \%$ of all plant species studied. According to the Food and Agriculture Organization of the United Nations, these species address ca. $60 \%$ of all harvested areas in $2019^{38}$. Besides, a considerable fraction of the studies raise concerns about the NP toxic effects on crop plants and the introduction of NPs in the food chain. Here one may perceive an opportunity to carry out studies using perennial and arboreal plant species such as those producing coffee, orange, olives, apples, pears, and vines among others.

Figure 3 reveals some aspects regarding the experimental design explored by the studies, e.g., particle size, use of positive experimental controls (i.e., the insoluble form of same NP composition at micrometer range or a soluble compound containing the element of interest), conditions of plant growth.

Since NP properties are intrinsically related to particle size, this is a piece of crucial information to be taken into account. Thereby, Figure 3a shows the size range of individual NPs, usually determined by scanning or transmission electron microscopy, and the 
hydrodynamic diameter of NPs dispersed in liquid media, measured by light scattering techniques. The NPs size ranged from a few nanometers up to hundreds of nm, with an average of $48 \mathrm{~nm}$, and a median size of $29 \mathrm{~nm}$. It is worth mentioning that Auffan et al. argue that nonbulk properties arise mainly for diameters below $30 \mathrm{~nm}^{39}$, which calls into question the account of a real nano effect for a majority of these studies.

NPs tend to agglomerate depending on physical-chemical interactions, and the primary particle size assessed by electron microscopy does not necessarily reflect the actual size in which they are going to reach plant tissues. The hydrodynamic diameter median size was 181 $\mathrm{nm}, c a$. 6-fold higher than the NP primary median size. The attempt of establishing a mathematical relationship between both size analyzes did not return a clear correlation.

From an agronomic standpoint, either for nutritional or pest management, the NP size is a key parameter. It is well-known that the release of ions can be controlled as a function of particle size since its dissolution rate is inversely proportional to the particle size $\mathrm{e}^{40-42}$. Ideally, one could develop nanoparticles of which element release rate could be controlled to match plant demand avoiding losses by volatilization, leaching, runoff, or strong adsorption in soil colloids.

Size also determines whether entire particles will enter into plant tissues, several size exclusion limits have been reported varying from ca. $5 \mathrm{~nm}$ up to $50 \mathrm{~nm}^{43-46}$. However, some studies have demonstrated the uptake and translocation of nanoparticles with diameters greater than the size range stated above $e^{45,47}$, which suggests that the uptake of intact particles depends also on NP composition, surface charge ${ }^{48}$, and plant species. The released ions may be taken up by roots or leaves, depending on the dosing method, and then these ions might eventually be precipitated within plants. Additionally, size and chemical reactivity can also be modified through the interaction of these nanomaterials with components of the environment, such as microorganisms and soil organic matter ${ }^{49}$. In this context, dealing with plants is even more 
challenging because roots can exude both protons, organic acids and siderophores that act as chelating agents ${ }^{50}$, as well as several secondary metabolites that might interact with the NPs ${ }^{51}$.

Figure $3 \mathrm{~b}$ shows that $71 \%$ of the articles do not employ bulk or soluble ionic positive controls, whereas $14 \%$ used soluble controls, $9 \%$ bulk control, and only $6 \%$ considered both soluble ionic and bulk controls. These figures often challenge attributing the observed results to properties arisen from the nano dimension of particles. For example, it is known that metallic nanoparticles can be transformed producing reactive ions able to bind into functional molecules in living organisms ${ }^{52}$. This leads to a myriad of harmful effects, such as destabilization of cell membrane integrity, alteration of cell osmotic balance, deactivation of enzymes, and reactive oxygen species (ROS) production, usually resulting in altered metabolism and cell damage ${ }^{52,53}$. Because of that, providing this kind of control could help to interpret the effects of nanomaterials ${ }^{52}$. Nevertheless, several papers aimed at comparing the effects of surface charge, type of coating, or particle size on uptake properties, and in such cases positive controls might not be useful or necessary.

Figure $3 \mathrm{c}$ shows the environment in which the experiments were carried out, revealing that $61 \%$ of them were performed in growth chamber conditions, whereas $c a .26 \%$ took place in greenhouses, and only a 5\% fraction were conducted under field conditions. Experiments that could not be grouped in these categories were named "ambient condition"; they correspond to $8 \%$ of reports. As researchers working on this topic, we acknowledge the difficulties involved in setting up a safe experiment with nanomaterials in the field. On the other hand, to facilitate real-world agricultural applications, this barrier must be overcome by organizing controlled field trials, because those are the equivalent to clinical trials in medicine for practical applications $^{54,55}$.

Growth chambers offer controlled temperature, air moisture, light, and water irrigation, while greenhouses usually grant controlled temperature and irrigation. Most of the experiments 
carried out either in growth chambers or greenhouse are performed in pots or trays. Nevertheless, it may subject plants to root space confinement and increase the probability of interaction between plant tissues and NPs or its released components leading to results that would likely differ from those experienced on field trials. A compromise between field and pot can be met by a mesocosms environment, which usually remains within a greenhouse with controlled external parameters, but at the same time, provides enough space for roots and allows NPs to diffuse across distinct environments. Prominent examples can be found in the studies by the groups of Lowry ${ }^{56,57}$, Wiesner ${ }^{58,59}$ and Colman ${ }^{60}$.

Figure $4 \mathrm{a}$, shows that $69 \%$ of the studies exposed plant root tissues to NPs, whereas only $14 \%$ and $13 \%$ exposed leaves and seeds, respectively. Within root exposure, $55 \%$ of them were carried out under growth solutions or agar-like media, which allow a great level of experimental control, but the results are hardly representative of soil. The preference for root exposure might arise from the fact that roots are the plant's organs designed for water and nutrient absorption, and hence it may unintentionally take up those NPs released into the environment. Nevertheless, although leaves are mainly responsible for transpiration and gas exchange, they can also absorb chemicals, including fertilizers ${ }^{61,62}$ and airborne NPs ${ }^{49}$.

Supposing that NPs will be employed as fertilizers, stimulants, or pesticides, their broadcast in the soil makes them more subject to losses. Additionally, the chemical interactions between NPs and soil colloids, such as clay and organic matter, and the effect of $\mathrm{pH}$, can modify the surface properties which will influence the bioavailability and mobility of $\mathrm{NPs}^{63}$.

From a practical point of view, the application of NPs in agriculture through seed and foliar treatment would lead to direct deposition of NPs on plants increasing the likelihood of assimilation. In this scenario, $\mathrm{ZnO}$ NPs applied to seeds enhance germination and increase root and shoot tissue length in maize, rice, and soybean plants ${ }^{21,64,65}$. Hence, the low number of studies evaluating this way of exposure is perceived as an opportunity that can be seized in 
future studies. Still, coffee plants that received foliar sprays of ca. $68 \mathrm{~nm} \mathrm{ZnO} \mathrm{NPs} \mathrm{at} 10 \mathrm{mg} \mathrm{L}^{-}$ ${ }^{1}$ and, after 40 days of treatment, presented $55 \%$ higher photosynthetic activity and $90 \%$ higher stomatal conductance compared to $\mathrm{ZnSO}_{4}$ and control treatments ${ }^{66}$. Also, foliar application of $\mathrm{Cu}$ NPs at $250 \mathrm{mg} \mathrm{L}^{-1}$ mitigated salt stress in tomatoes by improving the $\mathrm{Na}^{+} / \mathrm{K}^{+}$ratio. Besides, fruits of plants under salinity had their content of $\mathrm{Cu}$, vitamin $\mathrm{C}$, glutathione, and phenols significantly increased compared to controls ${ }^{67}$.

Figure $4 \mathrm{~b}$ shows that three-quarters of the studies carried out under hydroponics medium and soil span up between 21 and 90 days, respectively, with an 8 and 49 days median duration. The most frequently investigated crops shown in Figure 2, require around three to five months to complete their cycles, i.e., from sowing to harvesting. Here one could point to a gap, and hence an opportunity for long-term studies on the uptake of biotransformation of NPs. Considering the putative potential of nanotechnology to increase agricultural productivity, we should also focus on evaluating the impact of NPs on crop yield. Last, but not least, in the middle of a debate on whether the nutrient content of agricultural outputs has been declining compared to the past as a consequence of higher yields ${ }^{68,69}$, we should also consider evaluating more frequently the effect of NPs on the quality of vegetal products ${ }^{70,71}$.

Another parameter that might influence the results is the concentration range of NPs shown in Figure 4c. The median concentration of NPs dispersed in the liquid was $50 \mathrm{mg} \mathrm{L}^{-1}$ while the average concentration was $767 \mathrm{mg} \mathrm{L}^{-1}$. In a general-purpose solution for plant growth, essential macroelements such as potassium, calcium, and phosphorus are found at 235, 160, and $62 \mathrm{mg} \mathrm{L}^{-1}$, respectively. On the other hand, micronutrients as zinc, copper, and iron are present at $0.13,0.03$, and $1-3 \mathrm{mg} \mathrm{L}^{-1}$, respectively ${ }^{72}$. These concentrations correspond to the number of available nutrients, while the values presented in Figure 4c correspond to those NPs in which most of the elements are not supposed to be dissolved. It is noteworthy that the median 
concentration range of NPs dispersed in liquid media exceeds more than 10-fold that of essential micronutrients.

In regular hydroponics, the nutrients are depleted from the solution as they are absorbed by plants. Conversely, in a colloidal NP dispersion, one could expect a more constant concentration level due to equilibrium between solid and aqueous phases. Several studies indicate the fraction of dissolved ions in $\mathrm{ZnO}$ dispersions may vary from ca. 4 up to $9 \%{ }^{42,73}$, while for $\mathrm{CuO}$ these values reach $c a .0 .1$ up to $1.1 \%{ }^{74,75}$, and for $\mathrm{CeO}_{2}$ they range from $<0.1 \%$ up to $0.9 \%^{76,77}$. Nevertheless, the fraction of dissolved ions depends not only on the chemical composition of the NPs but also on the $\mathrm{pH}$ and chelating molecules present in the solution ${ }^{78}$. Among the surveyed papers, 103 out of 740 reported NPs tested at concentrations below $1 \mathrm{mg}$ $\mathrm{L}^{-1}, c a .27 \%$ of these studies investigated treatments based on silver or gold, while $c a .40 \%$ employed $\mathrm{Mn}, \mathrm{Cu}, \mathrm{Zn}$, and Fe plant micronutrients-based nanoparticles.

The range employed in soil was higher than in hydroponics, displaying median and average NPs of 125 and $1026 \mathrm{mg} \mathrm{kg}^{-1}$, respectively. The availability of nutrients depends on soil features, i.e., clay fraction content, $\mathrm{pH}$, organic matter content, and cation exchange capacity. Therefore, the adequate available concentration varies on soil texture, for phosphorus are slightly above $10 \mathrm{mg} \mathrm{kg}^{-1}$, and higher than 50,600, 2.5-5, 0.8-3, and 0.5-2 $\mathrm{mg} \mathrm{kg}^{-1}$ for $\mathrm{K}$, $\mathrm{Ca}, \mathrm{Fe}, \mathrm{Zn}$, and $\mathrm{Cu}$, respectively ${ }^{79}$.

From an environmental safety standing point, Reimann et al. determined the $\mathrm{HNO}_{3} / \mathrm{HCl} / \mathrm{H}_{2} \mathrm{O}$ extractable concentration of 53 elements in 2108 samples collected in agricultural and grazing lands of 33 European countries ${ }^{80}$. They found that geochemical threshold values, i.e., concentrations unusually high based on the value of the $98^{\text {th }}$ percentiles of the sampling, for $\mathrm{Zn}, \mathrm{Ag}, \mathrm{Cu}$, and $\mathrm{Ce}$ were $129,0.19,78$, and $81 \mathrm{mg} \mathrm{kg}^{-1}$, respectively. These elements comprise $c a .57 \%$ of the treatments in which NPs were dispersed into soils, sand or substrate, the median concentration of $\mathrm{Zn}, \mathrm{Ag}, \mathrm{Cu}$, and $\mathrm{Ce}$ in these studies were $200(n=264)$, 
$31(n=99), 100(n=106)$, and $250(n=140) \mathrm{mg} \mathrm{kg}^{-1}$, respectively ( $n$ corresponds to the number of treatments).

The amount of zinc employed in conventional fertilization depends on the crop and soil features, but it usually remains between a few to up to a dozen kilograms per hectare ${ }^{81-83}$ obtained high maize yield applying $\mathrm{Zn}$ at a rate of $11.5 \mathrm{~kg} \mathrm{ha}^{-1}\left(3.83 \mathrm{mg} \mathrm{kg}^{-1}\right.$ of $\mathrm{Zn}$ in soil), considering a typical soil layer $0.2 \mathrm{~m}$ deep and soil density of $1.5 \mathrm{~kg} \mathrm{dm}^{-3}$. To evaluate the potential gains offered by nanotechnology for fertilization, experiments aiming at replacing conventional bulk particulate or soluble fertilizers with nanoparticles should employ realistic field concentrations such as those above reported.

Thus, one should keep in mind that the nanosized properties of particles might have a crucial role in understanding the harmful effects of NPs. As well, the effects of high exposure concentrations should be accounted for. This puzzle could be more assertively solved if the results are backed up by adequate negative and positive experimental controls.

\section{Effects of nanomaterials on plants and soil microorganisms}

Once plants are exposed to NPs alongside all the variables discussed above, their morphology and physiology can impacted ${ }^{47,84,85}$. Aiming at making the comparison on equal terms, Figure 5 presents only data extracted from papers in which nanomaterials concentrations were reported on a weight/weight basis and roots were exposed to the treatments through soil/substrate or sand. It encompasses a total of 1060 treatments reported in 194 original articles. The myriad of plant responses evaluated in these studies was classified and grouped as 'harmful', 'beneficial', and 'beneficial and harmful', this latter comprising treatments that concomitantly presented both positive and negative impacts. Studies that did not observe any change were classified as 'no effect', while those that did not evaluate plant morphological and physiological responses were represented as 'not applicable'. Some of the plant responses reported by the authors were changes in plant height, root and shoot tissue length, fruit numbers 
and weight, crop yield, leaf area, protein, lycopene, b-carotene, carotenoids, chlorophyll $a$ and $b$ contents, and photosynthetic attributes, whose values higher than the control, statistically or suggested by the authors, were considered as beneficial effects. Consequently, their lower values were considered harmful ones. For other features, though, lower values indicate beneficial effects, and higher, in turn, harmful ones (e.g., fruiting and flowering time). Particularly, the increase of antioxidant enzyme activities, such as POD, APX, CAT, SOD was considered beneficial by some studies, and harmful by others. Since these results might reflect either an enhanced or overwhelmed plant responses to biotic and abiotic stresses, we followed the interpretation given by the authors.

Among the treatments, $37.5 \%$ resulted in harmful effects, $27.1 \%$ pointed out beneficial outcomes, $19.5 \%$ presented both harmful and beneficial consequences, $15.9 \%$ did not report changes compared to untreated plants, and $15 \%$ did not evaluate the effects of NPs on plants.

Notable NP effects on several aspects of agricultural-related research have been reported in recent years. Regarding biofortification, wheat seeds primed with ZnO NPs at 20$1000 \mathrm{mg} \mathrm{kg}^{-1}$ boosted the $\mathrm{Zn}$ content of the harvested grains. Compared with control, the concentration of $\mathrm{Zn}$ in grains was up to 3.3-fold higher and $\mathrm{ZnO}$ nanoparticles were more effective than $\mathrm{ZnSO}_{4}$. In addition to that, at moderate doses $\left(20 \mathrm{mg} \mathrm{kg}^{-1}\right)$ biomass and grain yield were also higher ${ }^{22}$.

Besides, some NP-related photocatalytic properties are claimed to benefit plant lightdependent reactions. In this scenario, root $\mathrm{ZnO}$ and foliar $\mathrm{Fe}$-based $\left(\mathrm{Fe}\right.$ and $\left.\mathrm{Fe}_{3} \mathrm{O}_{4}\right) \mathrm{NPs}$ exposure have also been reported to significantly increase the net photosynthetic rate of maize and tomato, leading to improve plant growth in both species ${ }^{86,87}$. Zinc oxide, $\mathrm{Si}$, and $\mathrm{TiO}_{2} \mathrm{NPs}$ exposure have also induced higher tolerance either to drought or salinity stress in mango, cucumber, and wheat plants, which might be related to endogenous NPs-driven boosting of plant's antioxidant enzymes ${ }^{88-90}$. Wheat plants grown in Cd-contaminated soils negatively 
affected photosynthesis, yield and caused oxidative stress damage in leaves. However, soil application of Fe nanoparticles at $25-100 \mathrm{mg} \mathrm{kg}^{-1}$ not only decreased Cd content in plant tissues but also increased photosynthesis, growth, and yield parameters ${ }^{91}$.

It is worth mentioning that exposing plant roots to nanoparticles might also influence soil microbial communities. Soil microorganisms play pivotal roles to assure soil quality since they carry out the decomposition of organic matter, assist plants in water and nutrient uptake ${ }^{92}$, and fixate most of the nitrogen used by legumes ${ }^{93}$ and a minor part of nitrogen employed by cereals. Hence, such microorganisms living in the rhizosphere ${ }^{94}$ improve plant development, yield, and resistance to diseases ${ }^{95}$. In this scenario, any possibility of NP-induced disruption of these ecological services must be a matter of concern ${ }^{96}$.

Despite their importance, Figure $5 b$ shows that the effect of NPs on soil microorganisms was assessed in only $12 \%$ of the treatments in 33 manuscripts out of 194 . This is a matter of great concern since the soil is expected to be the major sink of nanoparticles released into the environment ${ }^{97}$. Nevertheless, $28 \%$ of the treatments that assessed this parameter declared the soil microbial community did not change, while $33 \%$ reported that the either richness or abundance of microorganisms decreased, followed by $16 \%$ that increased, and finally $23 \%$ that reported both increase and decrease in soil microbiota. In this latter case, some papers reported modification of the structure of the community. According to Simonin \& Richaume ${ }^{98}$, inorganic nanoparticles (metal and metal oxide) are usually more detrimental to soil microorganisms than organic nanoparticles (fullerenes and carbon nanotubes).

Several studies associate the diversity and abundance of soil microorganisms with the applied NP concentrations. Albeit another key issue relies on the fact that the plant's developmental stages seem to interfere with microbial diversity in NP-amended soils. Carbon nanotubes at 0.1 and $100 \mathrm{mg} \mathrm{kg}^{-1} 1$ altered soybean rhizosphere prokaryotic community structure more intensely during the reproductive stage than the vegetative one ${ }^{99}$, whereas $\mathrm{Ag}$ 
NPs at $1 \mathrm{mg} \mathrm{kg}^{-1}$ showed a transient impact on the structure of the bacterial community during the transition from the seedling to the vegetative stage of wheat, but with a recovery to normal levels 49 days post-treatment ${ }^{100}$.

Some NPs are also known to cause antimicrobial effects to human and plant pathogens. Thereby, a study explored several application strategies of $\mathrm{Cu}_{3}(\mathrm{PO} 4)_{2} \cdot 3 \mathrm{H}_{2} \mathrm{O}$ nanosheets and $\mathrm{CuO}$ NPs resulting in suppressed root fungal disease induced by Fusarium oxysporum f. sp. niveum fungal in watermelon plants ${ }^{101}$. Moreover, soybean plants inoculated with Fusarium virguliforme and foliar sprayed with $\mathrm{CuO}, \mathrm{B}, \mathrm{MoO}_{3}$, or $\mathrm{ZnO}$ NPs presented a significant reduction of root rot severity involved in the sudden plant death syndrome ${ }^{102}$.

Medicago truncatula plants cultivated in a soil containing 1450, 100, or $2400 \mathrm{mg} \mathrm{kg}^{-1}$ of $\mathrm{Zn}, \mathrm{Ag}$, or Ti nanoparticles, respectively have negatively impacted microbial abundance in soils more significantly than those with bulk/dissolved treatments ${ }^{103}$. Conversely, $\mathrm{Ag}_{2} \mathrm{~S}$ nanoparticles were less harmful to tomato mycorrhizal symbiosis and the soil microbial community than $\mathrm{Ag}^{+104}$.

In some cases, soil microorganisms might mitigate nanoparticle toxicity to plants. Mycorrhizal fungi colonization in tomatoes cultivated in $\mathrm{Ag}$ nanoparticles spiked soil alleviated nanoparticle phytotoxicity by decreasing Ag accumulation in plant tissues ${ }^{105}$. Similarly, the root colonization rate significantly decreased when exposed to $\mathrm{ZnO}$ nanoparticles at and above $800 \mathrm{mg} \mathrm{kg}^{-1}$, but in spite of that arbuscular mycorrhizal fungi mitigated nanoparticle phytotoxic effect by decreasing $\mathrm{Zn}$ bioavailability and accumulation in maize ${ }^{106}$.

Plant responses depend on a complex parameters network. The box plots presented in Figure 6 correlates the effects observed in plants with the concentration of NPs applied into the soil as a function of (a), soil $\mathrm{pH}(\mathrm{b})$, and time of exposure (c). Although the highest mean value of the concentration of NPs in the soil come from treatments that pointed out beneficial effects 
in plants (ca. $\left.1200 \mathrm{mg} \mathrm{kg}^{-1}\right)$, median concentration values of the harmful $\left(400 \mathrm{mg} \mathrm{kg}^{-1}\right)$ and beneficial \& harmful $\left(200 \mathrm{mg} \mathrm{kg}^{-1}\right)$ effects are higher than the benefits and no effect (both at $100 \mathrm{mg} \mathrm{kg}^{-1}$ ) (Figure 6a). In other words, harmful effects might be generally associated with higher doses and vice-versa, however, due to lack of experimental standardization, it does not necessarily configure a cause-effect relationship.

In a range between 50 and $250 \mathrm{mg} \mathrm{kg}^{-1}, \mathrm{Fe}_{3} \mathrm{O}_{4}$ and $\mathrm{TiO}_{2}$ nanoparticles boosted phosphorus uptake, and shoot and root length and weight of lettuce ${ }^{107}$. At $500 \mathrm{mg} \mathrm{kg}^{-1} \mathrm{CeO}_{2}$ nanoparticles increased barley height by $34 \%$ and shoot biomass by $330 \%$ compared with control, but plants did not form grains ${ }^{108}$.

Besides concentration, soil characteristics play an important role in plant growth. Particularly, soil $\mathrm{pH}$ is one of the main properties which influence microorganism activity ${ }^{109}$ as well as nutrients solubility and availability ${ }^{110}$. The box plot shown in Figure $6 \mathrm{~b}$ indicates that mean and median values of soil $\mathrm{pH}$ were almost the same for all the treatments, close to neutral values, which suggests that soil $\mathrm{pH}$ might not be correlated with the effects caused by the nanoparticles.

Another important parameter that was not assessed in this data review was the effect of soil organic matter. The presence of humic acids and organic matter can alter the bioavailability of the nanomaterials in soils, as well as the presence of salts or changes of $\mathrm{pH}$ that result in the loss of nanoparticle stability ${ }^{44}$.

Concerning the time of exposure, small differences were found (Figure 6c). The median time of exposure in which nanoparticles caused harmful effects to plants was smaller than beneficial by a small margin (56 and 60 days, respectively). Beneficial $\&$ harmful effects presented a median time of exposure of 52 days, while the treatments that did not affect the plants lasted a median of 56 days. 
Altogether, the data presented in Figure 6 lead us to conclude that positive and/or negative effects as a response of a nanoparticle treatment are not solely a consequence of the applied concentration, soil $\mathrm{pH}$, or time of exposure, it seems to be more correlated with the nanoparticle type and plant species.

\section{What to expect about the future?}

Finally, the properties exhibited by nanoparticles may contribute to increase the agricultural yields and quality of products. Engineered NPs applied to agriculture can be targeted for soil amendments, seed coating, and foliar treatment.

Overall, it seems necessary to improve the description of experimental procedures. Regarding the experimental settings, a high number of NPs assays, frequently used in toxicity studies, might be supported by positive controls. At last, but not least, addressing NPs longterm experiments utilizing perennial plants is needed.

Replacing conventional fertilizers with nanofertilizers requires experiments employing compatible NP concentration ranges and longer time of exposure. The impacts on plant productivity from a commercial perspective (e.g., quantity and quality of edible parts) need to be reported in future studies. Costs involved in transforming salts or bulk particles into NPs might constitute a barrier unless the use-efficiency of NPs pays it off. Experiments in large mesocosms and field conditions are a key step that will contribute to mature nanotechnologies for agriculture. Also, it is important to consider studies under biotic and abiotic factors such as climate change conditions, and including soil amendments.

The effects of NPs on soil microorganisms must also be more frequently addressed, specific tests assuring that any commercial technology is not harmful to the soil microbiota should be demanded by regulators. Likewise, concentration thresholds for NPs in food and feed should be established aiming at avoiding possible threats to human and animal health. 
Overall, future studies must report and include in their scope, the size of NPs employed through multiple measurement techniques that capture both the primary particle size as well as agglomerate sizes in the dosing solutions. The NP suspension media and the surface chemistry of the NPs should be characterized, and controls with the associated agents but with the nanoparticles be performed to allow for determination of the active agents responsible for the effects observed.

The growth rate of agricultural outputs during the $18^{\text {th }}$ century raised so much concern that it led to the statement of the "Malthusian Catastrophe". The observers at that time could not forecast that the development and adoption of disruptive technologies, made possible by science, would promote the many-fold gains of productivity during the $20^{\text {th }}$ century. Perhaps, with the contribution of nanotechnology, the next productivity increase leap will come not by replacing current agricultural inputs, but by creating new ones. Sensing plant metabolism ${ }^{111}$ and quickly modulating it, hacking plant photosystems ${ }^{112}$, and stimulating plant functions are some examples of such technologies that will be available soon.

The use of nanotechnologies is often blamed by the literature and media, even though plants naturally take nutrients in the form of colloids and probably nanos. When we summarize the conclusions of these studies, $50 \%$ use objects that exceed the critical nano size, concentrations often unrelated to the intention, and protocols not always appropriate. This gives the impression that we still don't have a good knowledge of the properties of nanos, under optimized conditions of use.

Despite these shortcomings, $39 \%$ of the studies show beneficial effects or no effects at all, against $30 \%$ that show negative effects. These negative effects are not often compared to real stresses experienced by plants in the field. Altogether, these elements suggest that nanotechnology for agriculture deserves to be further explored. 


\section{Acknowledgments}

The authors are grateful to the São Paulo Research Foundation (grants 2020/07721-9, 201505942-0, 2016/50014-6, and 2017/21004-5), Brazilian National Council for Scientific and Technological (CNPq) (grant 407380/2016-7), Agrichem do Brasil S.A. (FEALQ\#10245-8), and Vittia Fertilizantes e Biológicos LTDA (FEALQ 10359-8). H.W.P. Carvalho. H. W. P. Carvalho is the recipient of a research productivity fellowship from the Brazilian National Council for Scientific and Technological Development (CNPq) (grant 306185/2020-2).

\section{Author Contributions}

This study was conceived by H.W.P.C., M.H.F.G., L.F.F., R.L., C.S., and S.G. The data collection was carried out by E.S.R., G.S.M., N.M.D., C.G.C., S.Z.R, M.H.F.G., and E.A. Data checking was carried out by H.W.P.C, E.S.R., G.S.M., N.M.D., C.G.C., S.Z.R, E.A, J.L.O., and A.ES.P. Data discussion and interpretation were performed by H.W.P.C, G.S.M., A.P.L., R.L., S.G, L.F.F, and C.S. The first manuscript draft was written by H.W.P.C, G.S.M, N.M.D., J.L.O., and A.ES.P. All authors edited the manuscript.

\section{Competing Interests statement}

The authors declare no competing interests.

\section{Literature cited}

1. Horlings, L. G. \& Marsden, T. K. Towards the real green revolution? Exploring the conceptual dimensions of a new ecological modernisation of agriculture that could 'feed the world'. Glob. Environ. Chang. (2011) doi:10.1016/j.gloenvcha.2011.01.004.

2. Godfray, H. C. J. et al. Food security: The challenge of feeding 9 billion people. Science (2010) doi:10.1126/science.1185383. 
3. FAO. Global agriculture towards 2050. High Lev. Expert Forum-How to Feed world $2050(2009)$

doi:http://www.fao.org/fileadmin/templates/wsfs/docs/Issues_papers/HLEF2050_Glob al_Agriculture.pdf.

4. ORGANIZATION., F. \& A. FUTURE OF FOOD AND AGRICULTURE 2018: Alternative Pathways to 2050. (FOOD \& AGRICULTURE ORG, 2018).

5. Tilman, D., Cassman, K. G., Matson, P. A., Naylor, R. \& Polasky, S. Agricultural sustainability and intensive production practices. Nature 418, 671-677 (2002).

6. Tilman, D., Balzer, C., Hill, J. \& Befort, B. L. Global food demand and the sustainable intensification of agriculture. Proc. Natl. Acad. Sci. (2011) doi:10.1073/pnas.1116437108.

7. Dayan, F. E., Cantrell, C. L. \& Duke, S. O. Natural products in crop protection. Bioorg. Med. Chem. 17, 4022-4034 (2009).

8. Van den Putte, A., Govers, G., Diels, J., Gillijns, K. \& Demuzere, M. Assessing the effect of soil tillage on crop growth: A meta-regression analysis on European crop yields under conservation agriculture. Eur. J. Agron. 33, 231-241 (2010).

9. Shah, F. \& Wu, W. Soil and Crop Management Strategies to Ensure Higher Crop Productivity within Sustainable Environments. Sustainability vol. 11 (2019).

10. Khan, I., Saeed, K. \& Khan, I. Nanoparticles: Properties, applications and toxicities. Arab. J. Chem. 12, 908-931 (2019).

11. Hinde, E. et al. Pair correlation microscopy reveals the role of nanoparticle shape in intracellular transport and site of drug release. Nat. Nanotechnol. 12, 81-89 (2017).

12. Khan, M., Ahamad, F. \& Fatima, T. Effect of Nanoparticles on Plant Pathogens. in 215-240 (2019). doi:10.1016/B978-0-12-815322-2.00009-2.

13. Swift, T. A., Oliver, T. A. A., Galan, M. C. \& Whitney, H. M. Functional 
nanomaterials to augment photosynthesis: evidence and considerations for their responsible use in agricultural applications. Interface Focus 9, 20180048 (2019).

14. Tighe-Neira, R. et al. Metallic nanoparticles influence the structure and function of the photosynthetic apparatus in plants. Plant Physiol. Biochem. 130, 408-417 (2018).

15. Gomes, M. H. F. et al. In Vivo Evaluation of Zn Foliar Uptake and Transport in Soybean Using X-ray Absorption and Fluorescence Spectroscopy. J. Agric. Food Chem. 67, (2019).

16. Kopittke, P. M., Lombi, E., Wang, P., Schjoerring, J. K. \& Husted, S. Nanomaterials as fertilizers for improving plant mineral nutrition and environmental outcomes. Environ. Sci. Nano 6, 3513-3524 (2019).

17. K.R, R., Thomas, S., Kalarikkal, N. \& K., J. Nanotechnology in controlled-release fertilizers. in 169-181 (2021). doi:10.1016/B978-0-12-819555-0.00010-8.

18. Ramírez-Rodríguez, G. B. et al. Reducing Nitrogen Dosage in Triticum durum Plants with Urea-Doped Nanofertilizers. Nanomaterials vol. 10 (2020).

19. Pérez-Álvarez, E. P. et al. Towards a more sustainable viticulture: foliar application of N-doped calcium phosphate nanoparticles on Tempranillo grapes. J. Sci. Food Agric. 101, 1307-1313 (2021).

20. Montanha, G. METADATA: Are nanomaterials making agriculture more productive? outputs from a metadata analysis of 2009-2020 research. (2021) doi:10.6084/m9.figshare.14575185.v1.

21. Montanha, G. S. et al. Zinc nanocoated seeds: an alternative to boost soybean seed germination and seedling development. SN Appl. Sci. 2, (2020).

22. Du, W., Yang, J., Peng, Q., Liang, X. \& Mao, H. Comparison study of zinc nanoparticles and zinc sulphate on wheat growth: From toxicity and zinc biofortification. Chemosphere 227, 109-116 (2019). 
23. Marucci, R. C. et al. Are Cerium Oxide Nanoparticles Transferred from Plants to the Aphid Myzus persicae (Hemiptera: Aphididae)? Florida Entomol. 102, 555-561 (2019).

24. Spielman-Sun, E. et al. Nanoparticle surface charge influences translocation and leaf distribution in vascular plants with contrasting anatomy. Environ. Sci. Nano 6, 25082519 (2019).

25. Körösi, L. et al. Nanostructured TiO2-induced photocatalytic stress enhances the antioxidant capacity and phenolic content in the leaves of Vitis vinifera on a genotypedependent manner. J. Photochem. Photobiol. B Biol. 190, 137-145 (2019).

26. Vance, M. E. et al. Nanotechnology in the real world: Redeveloping the nanomaterial consumer products inventory. Beilstein J. Nanotechnol. 6, 1769-1780 (2015).

27. Kaur, B. S., C., Z. T., Mausam, V., Y., S. R. \& D., T. R. Nanomaterials in the Environment. (American Society of Civil Engineers, 2015). doi:doi:10.1061/9780784414088

28. Król, A., Pomastowski, P., Rafińska, K., Railean-Plugaru, V. \& Buszewski, B. Zinc oxide nanoparticles: Synthesis, antiseptic activity and toxicity mechanism. $A d v$. Colloid Interface Sci. 249, 37-52 (2017).

29. Mishra, P. K., Mishra, H., Ekielski, A., Talegaonkar, S. \& Vaidya, B. Zinc oxide nanoparticles: a promising nanomaterial for biomedical applications. Drug Discov. Today 22, 1825-1834 (2017).

30. Vijayakumar, S., Vaseeharan, B., Malaikozhundan, B. \& Shobiya, M. Laurus nobilis leaf extract mediated green synthesis of $\mathrm{ZnO}$ nanoparticles: Characterization and biomedical applications. Biomed. Pharmacother. 84, 1213-1222 (2016).

31. Waghmode, M. S., Gunjal, A. B., Mulla, J. A., Patil, N. N. \& Nawani, N. N. Studies on the titanium dioxide nanoparticles: biosynthesis, applications and remediation. $S N$ 
Appl. Sci. 1, 310 (2019).

32. Ziental, D. et al. Titanium Dioxide Nanoparticles: Prospects and Applications in Medicine. Nanomaterials vol. 10 (2020).

33. Shi, H., Magaye, R., Castranova, V. \& Zhao, J. Titanium dioxide nanoparticles: a review of current toxicological data. Part. Fibre Toxicol. 10, 15 (2013).

34. Calderón-Jiménez, B. et al. Silver Nanoparticles: Technological Advances, Societal Impacts, and Metrological Challenges . Frontiers in Chemistry vol. 56 (2017).

35. Bezza, F. A., Tichapondwa, S. M. \& Chirwa, E. M. N. Fabrication of monodispersed copper oxide nanoparticles with potential application as antimicrobial agents. Sci. Rep. 10, $16680(2020)$.

36. Fatima, A., Singh, S. \& Prasad, S. M. Interaction Between Copperoxide Nanoparticles and Plants: Uptake, Accumulation and Phytotoxicity BT - Sustainable Agriculture Reviews 41: Nanotechnology for Plant Growth and Development. in (eds. Hayat, S., Pichtel, J., Faizan, M. \& Fariduddin, Q.) 143-161 (Springer International Publishing, 2020). doi:10.1007/978-3-030-33996-8_8.

37. Buchman, J. T., Hudson-Smith, N. V, Landy, K. M. \& Haynes, C. L. Understanding Nanoparticle Toxicity Mechanisms To Inform Redesign Strategies To Reduce Environmental Impact. Acc. Chem. Res. 52, 1632-1642 (2019).

38. Food and Agriculture Organization of the United Nations. FAOSTAT. 2020 http://www.fao.org/faostat/en.

39. Auffan, M. et al. Towards a definition of inorganic nanoparticles from an environmental, health and safety perspective. Nat. Nanotechnol. 4, 634-641 (2009).

40. David, C. A. et al. Dissolution Kinetics and Solubility of ZnO Nanoparticles Followed by AGNES. J. Phys. Chem. C 116, 11758-11767 (2012).

41. da Cruz, T. N. M. et al. A new glance on root-to-shoot in vivo zinc transport and time- 
dependent physiological effects of $\mathrm{ZnSO} 4$ and $\mathrm{ZnO}$ nanoparticles on plants. Sci. Rep. 9, $10416(2019)$.

42. da Cruz, T. N. M. et al. Shedding light on the mechanisms of absorption and transport of $\mathrm{ZnO}$ nanoparticles by plants via in vivo X-ray spectroscopy. Environ. Sci. Nano 4, 2367-2376 (2017).

43. Kińska, K., Jiménez-Lamana, J., Kowalska, J., Krasnodębska-Ostręga, B. \& Szpunar, J. Study of the uptake and bioaccumulation of palladium nanoparticles by Sinapis alba using single particle ICP-MS. Sci. Total Environ. 615, 1078-1085 (2018).

44. Pérez-de-Luque, A. Interaction of Nanomaterials with Plants: What Do We Need for Real Applications in Agriculture? . Frontiers in Environmental Science vol. 512 (2017).

45. Corredor, E. et al. Nanoparticle penetration and transport in living pumpkin plants: in situsubcellular identification. BMC Plant Biol. 9, 45 (2009).

46. Etxeberria, E., Gonzalez, P., Bhattacharya, P., Sharma, P. \& Ke, P. C. Determining the size exclusion for nanoparticles in citrus leaves. HortScience 51, 732-737 (2016).

47. Kah, M., Tufenkji, N. \& White, J. C. Nano-enabled strategies to enhance crop nutrition and protection. Nat. Nanotechnol. 14, 532-540 (2019).

48. Avellan, A. et al. Nanoparticle Uptake in Plants: Gold Nanomaterial Localized in Roots of Arabidopsis thaliana by X-ray Computed Nanotomography and Hyperspectral Imaging. Environ. Sci. Technol. 51, 8682-8691 (2017).

49. Karny, A., Zinger, A., Kajal, A., Shainsky-Roitman, J. \& Schroeder, A. Therapeutic nanoparticles penetrate leaves and deliver nutrients to agricultural crops. Sci. Rep. $\mathbf{8}$, 7589 (2018).

50. Sasse, J., Martinoia, E. \& Northen, T. Feed Your Friends: Do Plant Exudates Shape the Root Microbiome? Trends Plant Sci. 23, 25-41 (2018). 
51. Marslin, G., Sheeba, C. J. \& Franklin, G. Nanoparticles Alter Secondary Metabolism in Plants via ROS Burst . Frontiers in Plant Science vol. 8832 (2017).

52. Dev, A., Srivastava, A. K. \& Karmakar, S. Nanomaterial toxicity for plants. Environ. Chem. Lett. 16, 85-100 (2018).

53. Castro, B. et al. Stress-induced reactive oxygen species compartmentalization, perception and signalling. Nat. Plants 7, 403-412 (2021).

54. Pérez-de-Luque, A. Guest Edited Collection: Nanotechnology in agriculture. Sci. Rep. 10, $15738(2020)$.

55. Rearick, D. C., Telgmann, L., Hintelmann, H., Frost, P. C. \& Xenopoulos, M. A. Spatial and temporal trends in the fate of silver nanoparticles in a whole-lake addition study. PLoS One 13, e0201412 (2018).

56. Avellan, A. et al. Differential Reactivity of Copper- and Gold-Based Nanomaterials Controls Their Seasonal Biogeochemical Cycling and Fate in a Freshwater Wetland Mesocosm. Environ. Sci. Technol. 54, 1533-1544 (2020).

57. Stegemeier, J. P., Avellan, A. \& Lowry, G. V. Effect of Initial Speciation of Copperand Silver-Based Nanoparticles on Their Long-Term Fate and Phytoavailability in Freshwater Wetland Mesocosms. Environ. Sci. Technol. 51, 12114-12122 (2017).

58. Espinasse, B. P. et al. Comparative Persistence of Engineered Nanoparticles in a Complex Aquatic Ecosystem. Environ. Sci. Technol. 52, 4072-4078 (2018).

59. Geitner, N. K., Bossa, N. \& Wiesner, M. R. Formulation and Validation of a Functional Assay-Driven Model of Nanoparticle Aquatic Transport. Environ. Sci. Technol. 53, 3104-3109 (2019).

60. Colman, B. P. et al. Emerging Contaminant or an Old Toxin in Disguise? Silver Nanoparticle Impacts on Ecosystems. Environ. Sci. Technol. 48, 5229-5236 (2014).

61. Marschner, P. Marschner's Mineral Nutrition of Higher Plants. (2012). 
62. Fernández, V., Sotiropoulos, T. \& Brown, P. Foliar Fertilization: Scientific Principles and Field Pratices. (2013).

63. Kulikova, N. et al. Silver nanoparticles stabilized by humic substances adversely affect wheat plants and soil. J. Nanoparticle Res. 22, (2020).

64. Itroutwar, P. D., Kasivelu, G., Raguraman, V., Malaichamy, K. \& Sevathapandian, S. K. Effects of biogenic zinc oxide nanoparticles on seed germination and seedling vigor of maize (Zea mays). Biocatal. Agric. Biotechnol. 29, 101778 (2020).

65. Itroutwar, P. D. et al. Seaweed-Based Biogenic ZnO Nanoparticles for Improving Agro-morphological Characteristics of Rice (Oryza sativa L.). J. Plant Growth Regul. 39, 717-728 (2020).

66. Rossi, L., Fedenia, L. N., Sharifan, H., Ma, X. \& Lombardini, L. Effects of foliar application of zinc sulfate and zinc nanoparticles in coffee (Coffea arabica L.) plants. Plant Physiol. Biochem. 135, 160-166 (2019).

67. Pérez-Labrada, F. et al. Responses of Tomato Plants under Saline Stress to Foliar Application of Copper Nanoparticles. Plants vol. 8 (2019).

68. Davis, D. R. Declining Fruit and Vegetable Nutrient Composition: What Is the Evidence? HortScience horts 44, 15-19.

69. Marles, R. J. Mineral nutrient composition of vegetables, fruits and grains: The context of reports of apparent historical declines. J. Food Compos. Anal. 56, 93-103 (2017).

70. Zahedi, S. M., Karimi, M. \& Teixeira da Silva, J. A. The use of nanotechnology to increase quality and yield of fruit crops. J. Sci. Food Agric. 100, 25-31 (2020).

71. López-Vargas, E. R. et al. Foliar Application of Copper Nanoparticles Increases the Fruit Quality and the Content of Bioactive Compounds in Tomatoes. Applied Sciences vol. 8 (2018).

72. LAZAR, T. Taiz, L. and Zeiger, E. Plant physiology. 3rd edn. Ann. Bot. 91, 750-751 
(2003).

73. Savassa, S. M. et al. Effects of ZnO Nanoparticles on Phaseolus vulgaris Germination and Seedling Development Determined by X-ray Spectroscopy. ACS Appl. Nano Mater. 1, 6414-6426 (2018).

74. Santos-Rasera, J. R., Sant'Anna Neto, A., Rosim Monteiro, R. T., van Gestel, C. A. M. \& Pereira de Carvalho, H. W. Toxicity, bioaccumulation and biotransformation of $\mathrm{Cu}$ oxide nanoparticles in Daphnia magna. Environ. Sci. Nano 6, 2897-2906 (2019).

75. Duran, N. M. et al. X-ray Spectroscopy Uncovering the Effects of Cu Based Nanoparticle Concentration and Structure on Phaseolus vulgaris Germination and Seedling Development. J. Agric. Food Chem. 65, 7874-7884 (2017).

76. Schwabe, F. et al. Influence of two types of organic matter on interaction of $\mathrm{CeO} 2$ nanoparticles with plants in hydroponic culture. Chemosphere 91, 512-520 (2013).

77. Schwabe, F. et al. Dissolved cerium contributes to uptake of Ce in the presence of differently sized CeO2-nanoparticles by three crop plants. Metallomics 7, 466-477 (2015).

78. Dahle, J. T., Livi, K. \& Arai, Y. Effects of $\mathrm{pH}$ and phosphate on $\mathrm{CeO} 2$ nanoparticle dissolution. Chemosphere 119, 1365-1371 (2015).

79. Fageria, N. K. \& Baligar, V. C. NUTRIENT AVAILABILITY. in (ed. Hillel, D. B. T.E. of S. in the E.) 63-71 (Elsevier, 2005). doi:https://doi.org/10.1016/B0-12-3485304/00236-8.

80. Reimann, C. et al. GEMAS: Establishing geochemical background and threshold for 53 chemical elements in European agricultural soil. Appl. Geochemistry 88, 302-318 (2018)

81. Sutradhar, A. K., Kaiser, D. E. \& Behnken, L. M. Soybean Response to Broadcast Application of Boron, Chlorine, Manganese, and Zinc. Agron. J. 109, 1048-1059 
(2017).

82. Ruffo, M., Olson, R. \& Daverede, I. Maize Yield Response to Zinc Sources and Effectiveness of Diagnostic Indicators. Commun. Soil Sci. Plant Anal. 47, 137-141 (2016).

83. Liu, D.-Y. et al. Soil application of zinc fertilizer could achieve high yield and high grain zinc concentration in maize. Plant Soil 411, 47-55 (2017).

84. Hofmann, T. et al. Technology readiness and overcoming barriers to sustainably implement nanotechnology-enabled plant agriculture. Nat. Food 1, 416-425 (2020).

85. Zuverza-Mena, N. et al. Exposure of engineered nanomaterials to plants: Insights into the physiological and biochemical responses-A review. Plant Physiol. Biochem. 110, 236-264 (2017).

86. Faizan, M., Faraz, A. \& Hayat, S. Effective use of zinc oxide nanoparticles through root dipping on the performance of growth, quality, photosynthesis and antioxidant system in tomato. J. Plant Biochem. Biotechnol. 29, 553-567 (2020).

87. Li, P. et al. Insight into the interaction between Fe-based nanomaterials and maize (Zea mays) plants at metabolic level. Sci. Total Environ. 738, 139795 (2020).

88. Elsheery, N. I., Helaly, M. N., El-Hoseiny, H. M. \& Alam-Eldein, S. M. Zinc Oxide and Silicone Nanoparticles to Improve the Resistance Mechanism and Annual Productivity of Salt-Stressed Mango Trees. Agronomy vol. 10 (2020).

89. Lu, L. et al. Mn3O4 nanozymes boost endogenous antioxidant metabolites in cucumber (Cucumis sativus) plant and enhance resistance to salinity stress. Environ. Sci. Nano 7, 1692-1703 (2020).

90. Faraji, J. \& Sepehri, A. Exogenous Nitric Oxide Improves the Protective Effects of TiO2 Nanoparticles on Growth, Antioxidant System, and Photosynthetic Performance of Wheat Seedlings Under Drought Stress. J. Soil Sci. Plant Nutr. 20, 703-714 (2020). 
91. Adrees, M. et al. Simultaneous mitigation of cadmium and drought stress in wheat by soil application of iron nanoparticles. Chemosphere 238, 124681 (2020).

92. Ferreira, D. A. et al. Soil Microbial Diversity Affects the Plant-Root Colonization by Arbuscular Mycorrhizal Fungi. Microb. Ecol. (2020) doi:10.1007/s00248-020-01502Z.

93. Schwember, A. R., Schulze, J., del Pozo, A. \& Cabeza, R. A. Regulation of Symbiotic Nitrogen Fixation in Legume Root Nodules. Plants vol. 8 (2019).

94. Rosenblueth, M. et al. Nitrogen Fixation in Cereals . Frontiers in Microbiology vol. 91794 (2018).

95. Qu, Q. et al. Rhizosphere Microbiome Assembly and Its Impact on Plant Growth. $J$. Agric. Food Chem. 68, 5024-5038 (2020).

96. Dinesh, R., Anandaraj, M., Srinivasan, V. \& Hamza, S. Engineered nanoparticles in the soil and their potential implications to microbial activity. Geoderma 173-174, 1927 (2012).

97. Mishra, S., Singh, H. B. \& Yang, X. Creating a global database "Nanomaterials in the soil environment": future need for the terrestrial ecosystem. Energy, Ecol. Environ. 4, 271-285 (2019).

98. Simonin, M. \& Richaume, A. Impact of engineered nanoparticles on the activity, abundance, and diversity of soil microbial communities: a review. Environ. Sci. Pollut. Res. 22, 13710-13723 (2015).

99. Ge, Y. et al. Carbonaceous Nanomaterials Have Higher Effects on Soybean Rhizosphere Prokaryotic Communities During the Reproductive Growth Phase than During Vegetative Growth. Environ. Sci. Technol. 52, 6636-6646 (2018).

100. Liu, G. et al. The Effects of Low Concentrations of Silver Nanoparticles on Wheat Growth, Seed Quality, and Soil Microbial Communities. Water, Air, Soil Pollut. 228, 
348 (2017).

101. Borgatta, J. et al. Copper Based Nanomaterials Suppress Root Fungal Disease in Watermelon (Citrullus lanatus): Role of Particle Morphology, Composition and Dissolution Behavior. ACS Sustain. Chem. Eng. 6, 14847-14856 (2018).

102. Peréz, C. D. P. et al. Metalloid and Metal Oxide Nanoparticles Suppress Sudden Death Syndrome of Soybean. J. Agric. Food Chem. 68, 77-87 (2020).

103. Judy, J. D. et al. Nanomaterials in Biosolids Inhibit Nodulation, Shift Microbial Community Composition, and Result in Increased Metal Uptake Relative to Bulk/Dissolved Metals. Environ. Sci. Technol. 49, 8751-8758 (2015).

104. Judy, J. D. et al. Effects of silver sulfide nanomaterials on mycorrhizal colonization of tomato plants and soil microbial communities in biosolid-amended soil. Environ. Pollut. 206, 256-263 (2015).

105. Noori, A., White, J. C. \& Newman, L. A. Mycorrhizal fungi influence on silver uptake and membrane protein gene expression following silver nanoparticle exposure. $J$. Nanoparticle Res. 19, 66 (2017).

106. Wang, F. et al. Arbuscular mycorrhizae alleviate negative effects of zinc oxide nanoparticle and zinc accumulation in maize plants - A soil microcosm experiment. Chemosphere 147, 88-97 (2016).

107. Zahra, Z. et al. Metallic Nanoparticle (TiO2 and Fe3O4) Application Modifies Rhizosphere Phosphorus Availability and Uptake by Lactuca sativa. J. Agric. Food Chem. 63, 6876-6882 (2015).

108. Rico, C. M. et al. Physiological and biochemical response of soil-grown barley (Hordeum vulgare L.) to cerium oxide nanoparticles. Environ. Sci. Pollut. Res. 22, $10551-10558$ (2015).

109. Stark, S., Männistö, M. K. \& Eskelinen, A. Nutrient availability and pH jointly 
constrain microbial extracellular enzyme activities in nutrient-poor tundra soils. Plant Soil 383, 373-385 (2014).

110. Sims, J. T. Soil pH Effects on the Distribution and Plant Availability of Manganese, Copper, and Zinc. Soil Sci. Soc. Am. J. 50, 367-373 (1986).

111. Lew, T. T. S. et al. Species-independent analytical tools for next-generation agriculture. Nat. Plants 6, 1408-1417 (2020).

112. Giraldo, J. P. et al. Plant nanobionics approach to augment photosynthesis and biochemical sensing. Nat. Mater. 13, 400-408 (2014).

113. Efficiency, N. U. S. E. Plant Nutrition 2: Macronutrients (N, P, K, S, Mg, and Ca). Plant Cell 26, tpc.114.tt1214 (2014).

114. Marschner, P. Marschner's Mineral Nutrition of Higher Plants: Third Edition. Marschner's Mineral Nutrition of Higher Plants: Third Edition (2011). doi:10.1016/C2009-0-63043-9.

\section{Metadata}

The raw data, including their proper references, used for preparing each figure is available at Figshare repository ${ }^{20}$

\section{Figures}




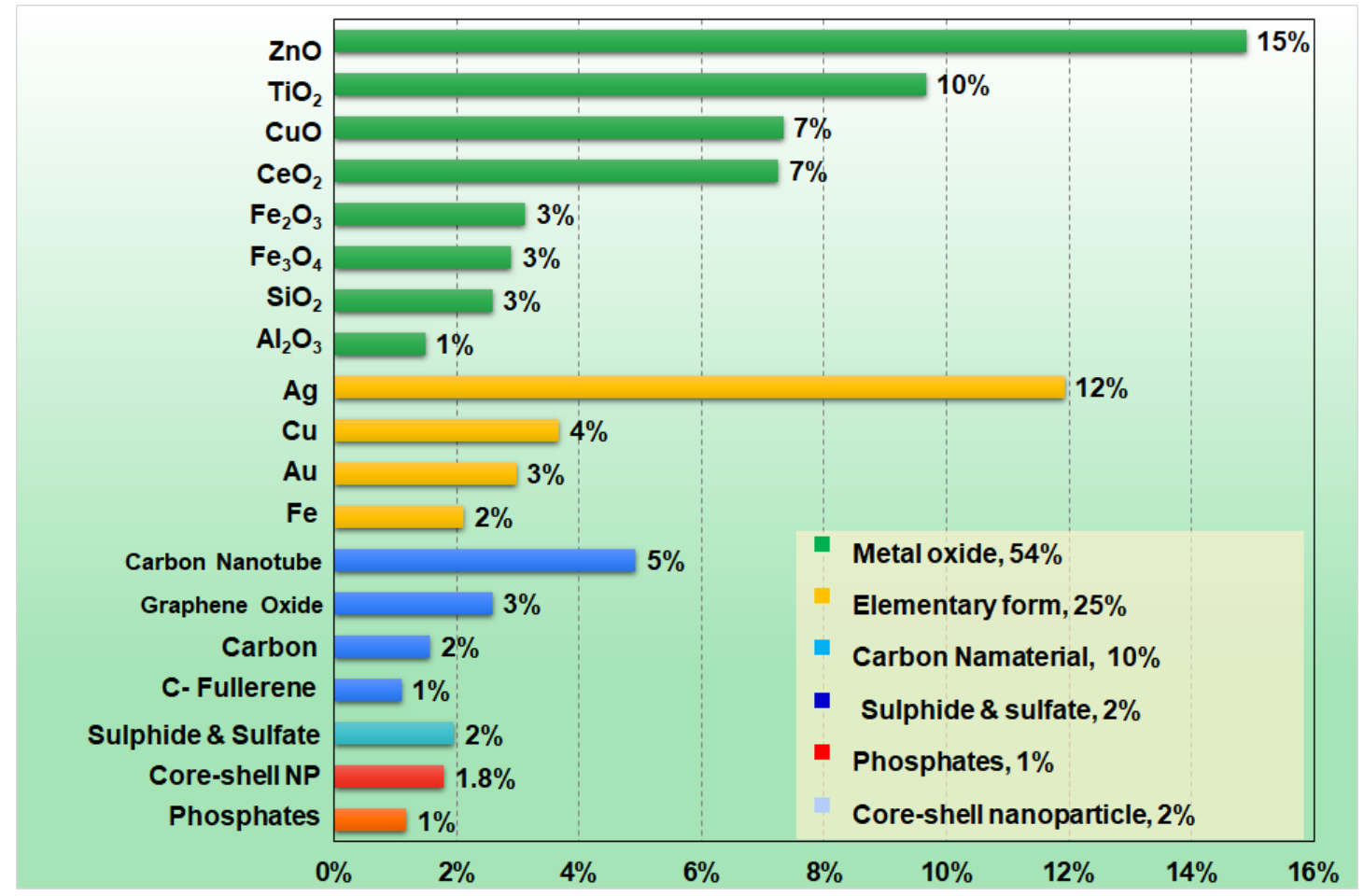

Figure 1. Most frequently employed NPs ( $n=1282$ NPs) found in 996 original research articles published between 2009 and 2020. Each bar color encompasses an NP group, namely, metal oxides, elementary form-ones, carbonbased, sulfide and sulfates, core-shells, and phosphate. Particles whose frequency was smaller than 1\%, i.e., nanohydroxides, mixed oxides, among others are not shown. For the complete data, please check Table S1 at the Electronic Supplementary Information. The estimated data uncertainty is below $3.2 \%$.

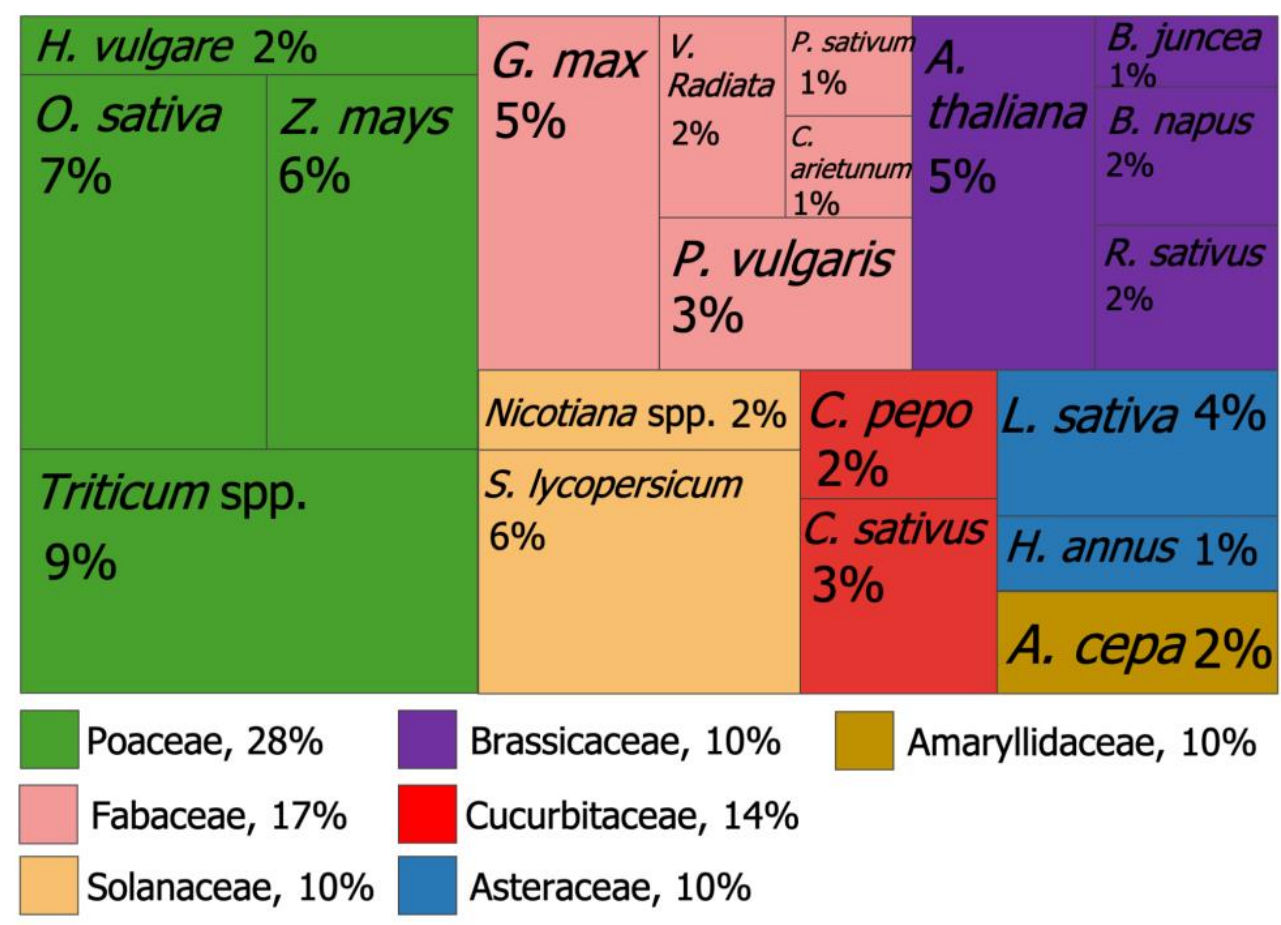


Figure 2. Frequency of plant species and families found in 996 original research articles published between 2009 and 2020, summing up an amount 1196 plants from 202 species and 63 families. Those species and families encompassing frequencies smaller than $1 \%$, respectively, were herein classified as others. The worksheet at the Supplementary Information presents the full record of both species and family. The estimated data uncertainty is below $1.9 \%$.

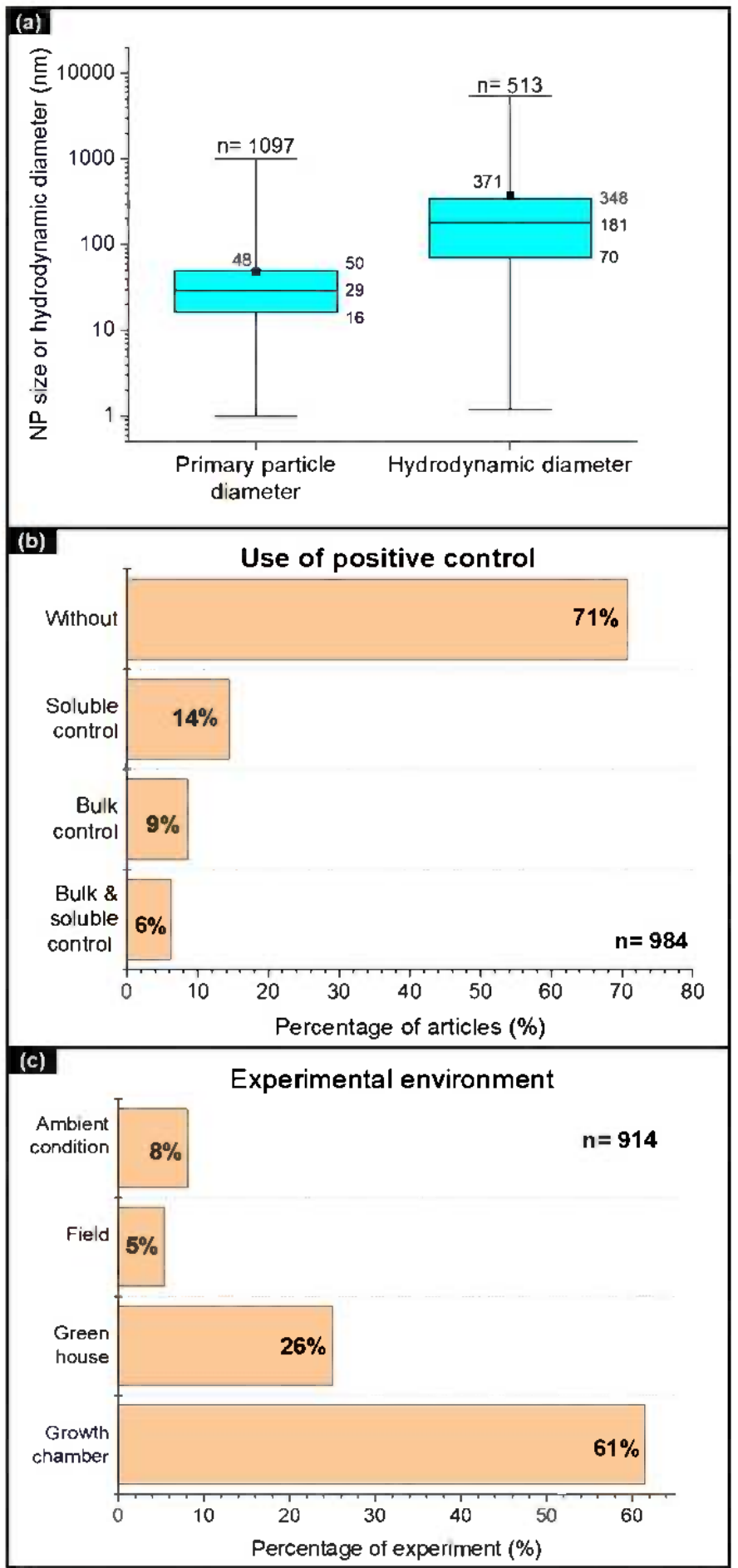


Figure 3. (a) Boxplots of primary particle diameter and hydrodynamic diameter of NPs. The central line points out the median, whereas the black dots indicate the mean value, the estimated data uncertainty is below $3.7 \%$. Noteworthy highlights are that from all the articles consulted, $20 \%$ did not provide any, or supplied incomplete information about NP primary size, while 63\% did not report NPs hydrodynamic diameter. (b) Frequency of studies that reported use of positive control, i.e., either bulk or soluble compounds, at the same experiment as NPs, the estimated data uncertainty is below $4.3 \%$. (c) Frequency of the environment in which the experiments were carried out, namely, ambient condition (without control of light and temperature factors), field, greenhouse, and growth chamber. The estimated data uncertainty is below $2.9 \%$. In Figure $3 a n$ represents the number of treatments, in Figure $3 \mathrm{~b} n$ indicates the number of papers, and in Figure $3 \mathrm{c} n$ represents the number of experimental conditions. 


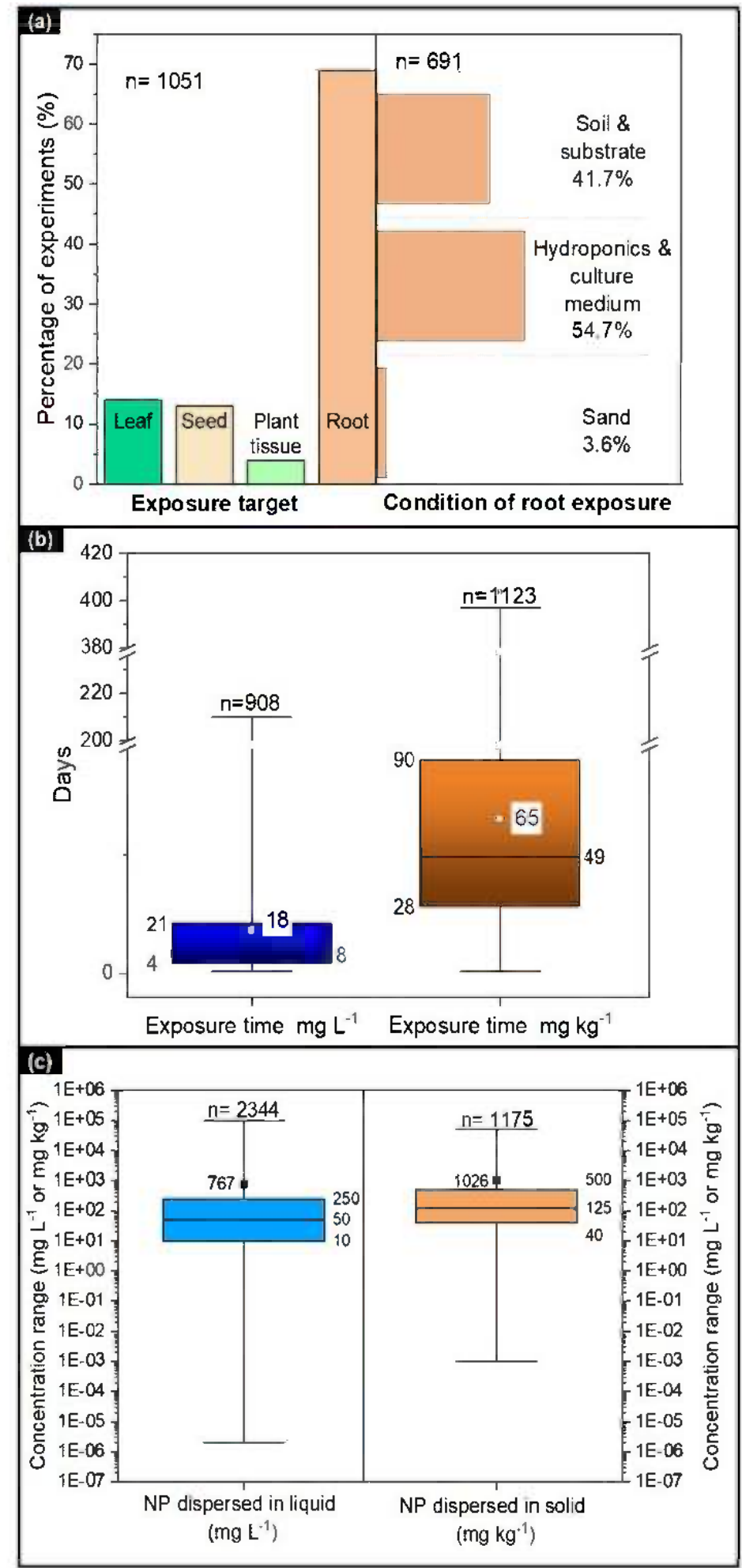

Figure 4. (a) Plant part or plant organ exposed to NPs, and the media employed in case of root exposure, the estimated data uncertainty is below 3.8\%. (b) Boxplots presenting the exposure time of plants to NPs either dispersed in liquid solutions or soli, the estimated data uncertainty is below 2.4\%. (c) Boxplots of NPs concentration range either dispersed in liquid or solid, the estimated data uncertainty is below 4.2\%. Center lines point out the median, whereas the dots indicate the mean values in $\mathrm{b}$ and. In Figure $4 \mathrm{a} n$ represents the number of experiments, in Figure $4 \mathrm{~b} n$ indicates the number of exposure times described by the studies, and Figure $4 \mathrm{c} n$ represents the number of treatments reported by the manuscripts. 


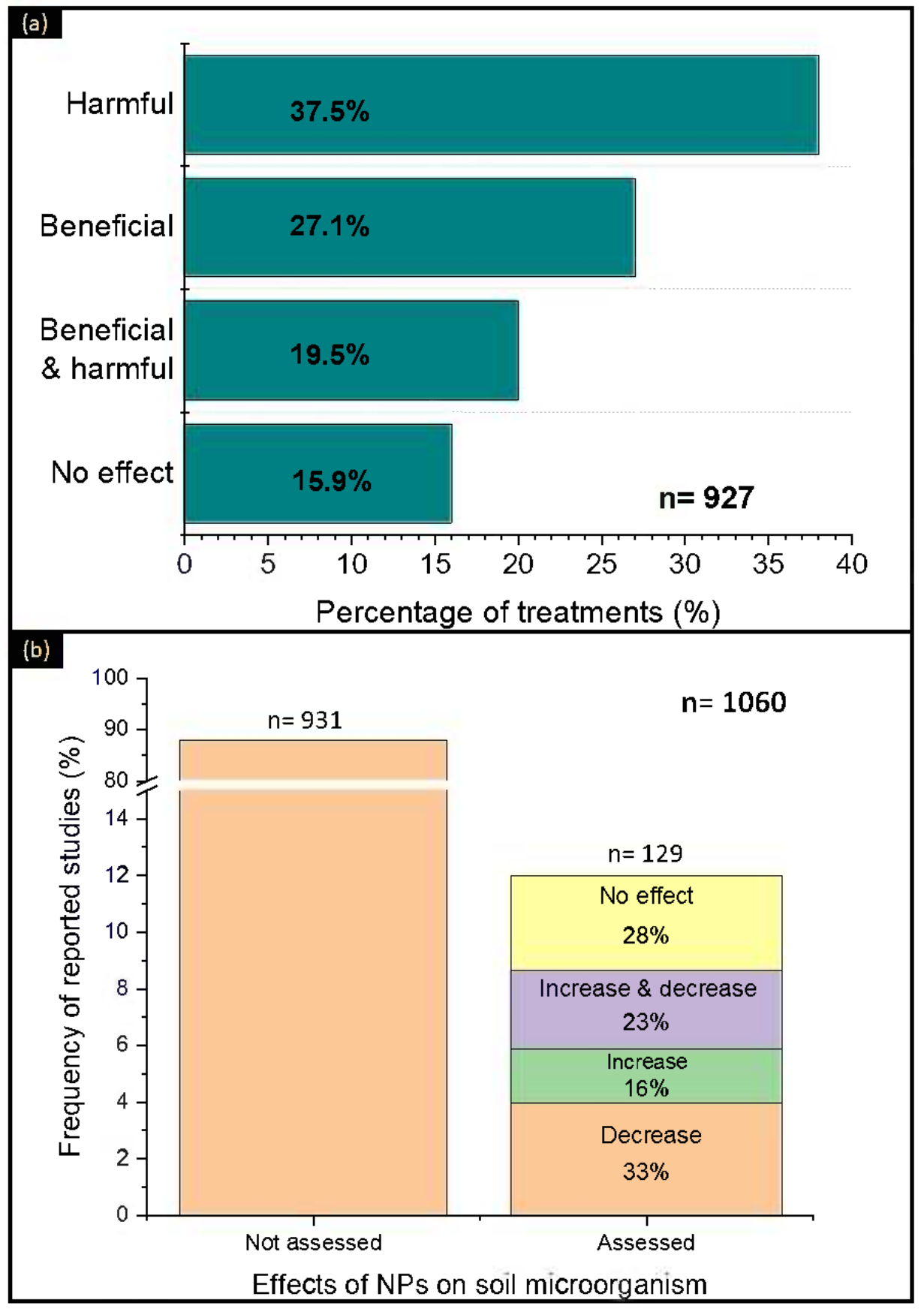

Figure 5. (a) Frequency of reported effects of NPs on plants whose roots were exposed to the treatments in solid media, i.e., soil or sand. 'Beneficial \& harmful' effect comprises treatments reporting overlapped positive and negative effects, whereas the 'No effect' refers to those reporting no changes compared to the negative control group, and "Not applicable" encompasses studies/treatments that did not evaluate plant biological responses as an effect of NPs exposure. The estimated data uncertainty is below $6.6 \%$. (b) Frequency of treatments that reported effects of NPs soil microbiota. The double-checking did not return a measurable error. In both figures $n$ refers to the number of treatments reported by the studies. Data computed from 194 original research articles published between 2009 and 2020. 


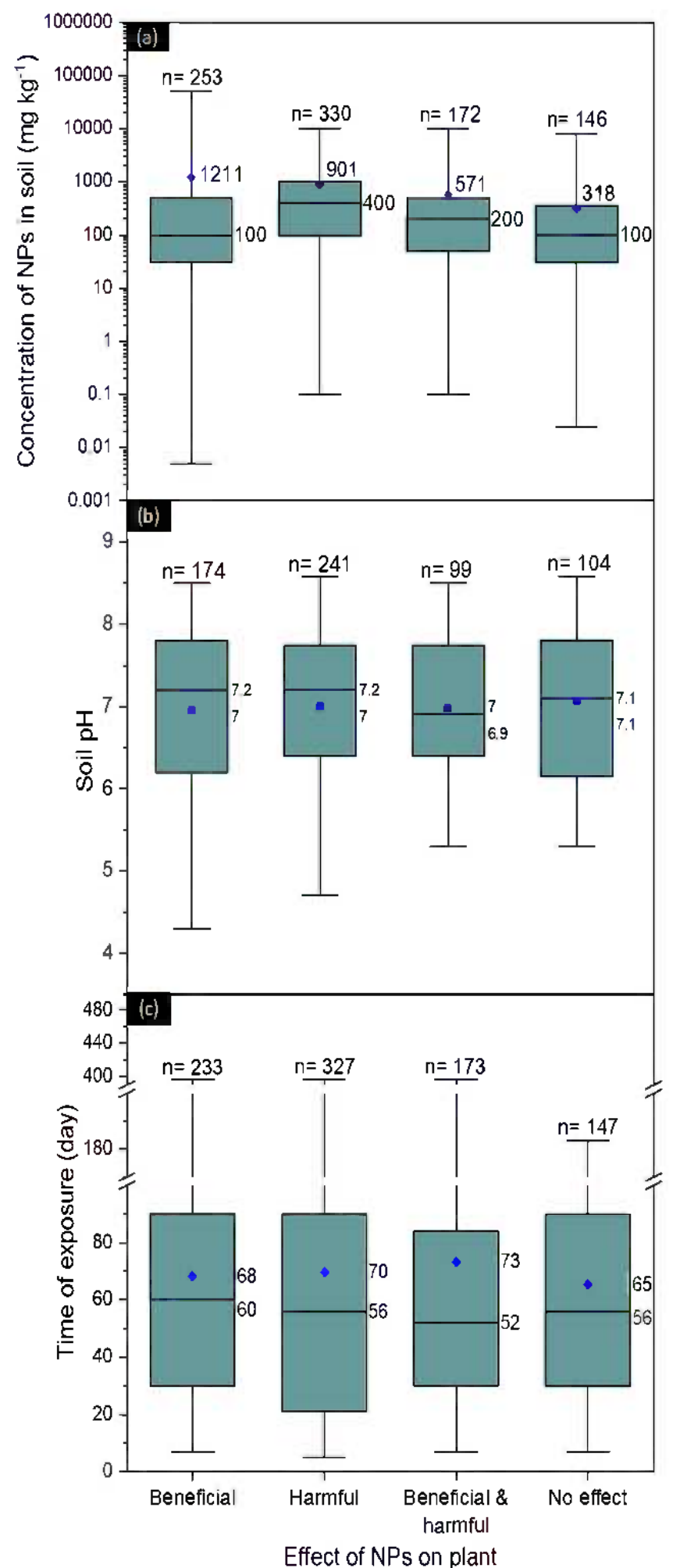

Figure 6. Boxplots of soil-amended NPs concentration (a), soil pH (b), and NPs exposure time to plants (c) as results of NPs effects in plants root-exposed on soil-based medium. Center lines point out the median, whereas the blue dots sign the mean values. Data $(n=1060$ treatments) computed from 194 original research articles published between 2009 and 2020. 


\section{ELECTRONIC SUPPLEMENTARY INFORMATION}

\section{Manuscript search and selection}

The present study was carried out by consulting 996 Web of Science indexed research articles related to nanomaterials and plants published between January, 2009 and September, 2020. For article selection at the Web of Science platform, we employed the following and booleans $(\mathrm{TOPIC}=$ nanoparticle OR nanomaterial OR nanotechnology $)$ AND $($ TOPIC $=$ seed OR plant OR agriculture).

The search returned around 4000 papers. The 996 papers employed in the present study were selected because they presented studies either dealing with the uptake and fate of nanoparticles in plants or depicted how nanoparticles affected plants. Despite interferences with plant development and the metabolism itself, important issues like diseases, salt and drought stresses were also considered. Papers that observed how nanomaterials interact with the plant surrounding environment, like the soil microbiota, were also taken into account. Some examples of papers that were rejected during the search are those related to synthesis of nanoparticles using plant extracts, use of nanomaterials in soil remediation and those focused only on pest control. Several rejected papers were related to the release of pesticides, essential oils, and other substances. Review articles were also excluded from the search. All selected articles were examined individually, and the selected information was used for composing the database.

The criteria used for data mining were as follows. First, spreadsheets were filled with the following information: digital object identifier (DOI) code, publication year, applied concentration, nanoparticle composition, particle and hydrodynamic size, plant species, exposure time, type of control used (soluble ionic compounds, bulk/micrometric counterparts, negative control), way of exposure, soil $\mathrm{pH}$, effects on soil microorganisms, experimental 
environment, and effects on plants. Thereafter, each information was separated into different worksheets with data organization specific criteria.

\section{Nanoparticle composition}

The following criteria were adopted to organize the nanoparticle composition data in the worksheets (data corresponding to Figure 1). The DOI code of each article and its respective nanoparticle composition were placed in the first two columns, then the frequency of each kind of NP was calculated using the function COUNTIF on Excel software. NPs were classified as "nutrient" or "non-nutrient" to the plants and categorized into metal oxide, elementary form, carbon nanomaterial, sulphide and sulfate, phosphate, carbon, core-shell nanoparticle, and others (hydroxides, mixed oxides, polymeric). The core-shell group refers to NPs coated with another chemical element. However, NPs coated with organic molecules, such as citrate-coated Ag NPs, were grouped following their elementary composition. Also, it is important to highlight that some articles studied more than one kind of NP, thus the DOI code of these articles is repeated in the worksheet, for this reason, the number of data entries (n) in Figure 1 is 1282 even though the number of consulted articles is 996 .

We based the classification of plant nutrients according to Marschner ${ }^{113}$ to categorize the NPs as "nutrient" or "non-nutrient". However, we did not consider silicon as a nutrient since this element is not essential for all plants. Besides that, potentially toxic NPs like $\mathrm{CdS} / \mathrm{ZnS}$ were also categorized as "non-nutrient" even though they contain a mineral nutrient. 
Table S1. Nanoparticle composition found in 1282 entries of 966 manuscripts.

\begin{tabular}{|c|c|c|c|}
\hline Composition & chemical formula & Frequency & Frequency (\%) \\
\hline Metal oxide, $\mathbf{5 4 \%}$ & $\mathrm{ZnO}$ & 191 & 14.9 \\
\hline Metal oxide, $\mathbf{5 4 \%}$ & $\mathrm{CeO} 2$ & 93 & 7.3 \\
\hline Metal oxide, $\mathbf{5 4 \%}$ & $\mathrm{TiO} 2$ & 124 & 9.7 \\
\hline Metal oxide, $\mathbf{5 4 \%}$ & $\mathrm{Fe} 3 \mathrm{O} 4$ & 37 & 2.9 \\
\hline Metal oxide, $\mathbf{5 4 \%}$ & $\mathrm{CuO}$ & 94 & 7.3 \\
\hline Metal oxide, $\mathbf{5 4 \%}$ & $\mathrm{SiO} 2$ & 33 & 2.6 \\
\hline Metal oxide, $\mathbf{5 4 \%}$ & $\mathrm{Fe} 2 \mathrm{O} 3$ & 40 & 3.1 \\
\hline Metal oxide, $\mathbf{5 4} \%$ & $\mathrm{Al} 2 \mathrm{O} 3$ & 19 & 1.5 \\
\hline Metal oxide, $\mathbf{5 4 \%}$ & Other & 57 & 4.4 \\
\hline Elementary form, $\mathbf{2 5 \%}$ & $\mathrm{Au}$ & 38 & 3.0 \\
\hline Elementary form, $\mathbf{2 5 \%}$ & $\mathrm{Ag}$ & 153 & 11.9 \\
\hline Elementary form, $\mathbf{2 5 \%}$ & $\mathrm{Cu}$ & 47 & 3.7 \\
\hline Elementary form, $\mathbf{2 5 \%}$ & $\mathrm{Fe}$ & 27 & 2.1 \\
\hline Elementary form, $\mathbf{2 5 \%}$ & Other & 54 & 4.2 \\
\hline Carbon Nanomaterial, $10 \%$ & Carbon & 20 & 1.6 \\
\hline Carbon Nanomaterial, $10 \%$ & C-Fullerene & 14 & 1.1 \\
\hline Carbon Nanomaterial, $10 \%$ & Graphene Oxide & 33 & 2.6 \\
\hline Carbon Nanomaterial, $10 \%$ & Carbon Nanotube & 63 & 4.9 \\
\hline Carbon Nanomaterial, $10 \%$ & Other & 4 & 0.3 \\
\hline Sulphide \& sulfate, $2 \%$ & Sulphide \& sulfate & 25 & 2.0 \\
\hline Phosphates, $1 \%$ & Phosphates & 15 & 1.2 \\
\hline Core-shell nanoparticle, $2 \%$ & Core-shell nanoparticle & 23 & 1.8 \\
\hline $\begin{array}{l}\text { Others } \\
\text { (hydroxides, mixed oxides, } \\
\text { polymeric), } 6 \%\end{array}$ & other & 78 & 6.1 \\
\hline Total & & 1282 & 100 \\
\hline
\end{tabular}

\section{Plant species}

The plant species worksheet displays the plants used on each of the selected articles. It was organized by DOI code, scientific name, and its respective family, as represented in Figure 2. It is important to highlight that, for the studies that mention just the plant's common name, we searched its scientific name and used only the first name of the binomial nomenclature which identifies its genus. Thus, we computed 1189 plants used in the 996 researched articles. The frequency of each species was calculated by the COUNTIF function as well. The species with a frequency below $1 \%$ are not reported in the corresponding figure. 


\section{Nanoparticle size}

The worksheet that shows the NP size was arranged according to the size given by the manufacturer or measured by the authors using electronic microscopy or other methods, followed by the hydrodynamic diameter. In articles that reported both manufacture and authors measured particle size, the latter was considered. For those papers reported polydisperse nanoparticles of a certain size range, the average value was considered. For example, (10.15244/pjoes/99239) reported $\mathrm{ZnO}$ particles between $50-150 \mathrm{~nm}$, in this case, the worksheet presents $100 \mathrm{~nm}$.

The standard deviation informed by some authors was disregarded. For the articles that reported size values with a signal of greater $(>)$ or less than $(<)$, we just considered the values. For example, (10.1016/j.chemosphere.2019.03.168) reported that their ZnO NPs have a size “<100 nm”, in which only $100 \mathrm{~nm}$ was maintained in the worksheet.

The size of carbon nanotubes, graphene, and nano-chitosan were considered as 'not applicable', since the articles reported two size values (length and width) or not informed any.

Articles that did not report size, or in which the information was not clear were considered as 'not applicable'.

For obtaining the information on NP primary diameter we employed 982 papers and 223 were considered as 'not applicable'. For the hydrodynamic diameter we employed 982 papers and 624 were considered as 'not applicable'.

\section{Positive experimental controls}

We verified the use of both bulk (microparticles) and soluble compounds and characterized it as a positive control. Bulk particles were considered positive controls when presenting the same composition as the NPs. On the other hand, the soluble control is stated as the effect of the elements ionic form studied on the plants. Some authors used different 
elements, but with a similar effect as the soluble control. One should mention that, in principle, there is no soluble control for carbon-based nanomaterials such as nanotubes, graphene or carbon quantum dots, however graphite could be used as a proxy for micrometric control. Likewise, one should acknowledge that soluble titanium salts are not common and hence it is difficult to employ such positive control. When nanoparticles were used to sorb other nutrients, complete growth solutions were not considered as positive dissolved control.

\section{Experimental environment}

Four groups of the experimental environment were formed: i) greenhouse, which includes the experiments maintained inside a greenhouse; glasshouse, or screen house with some conditions controlled, such as temperature, photoperiod, watering, and humidity; ii) field, considering experiments that were maintained under field conditions with plants grown in soil without any control of temperature, photoperiod, and humidity; iii) growth chamber, which determines the experiments maintained in a growth chamber, germination chamber, laboratory, or in vitro conditions with some controlled parameters, such as temperature, photoperiod, watering, and humidity; iv) ambient conditions refers to all the experiments performed on environments that did not fit into the previous categories, such as experiments in a recipient (vase, tube, plastic bag) maintained under environmental conditions such as sunlight, weather or ambient atmosphere, indoor or outdoor with room temperature and natural conditions. It also included a few mesocosms experiments.

A total of 991 documents were analyzed. Among them, 892 were employed to build Figure $3 c$ and 99 did not inform, or it was not clear, the experimental environment in which the plants were subjected to the treatments.

\section{Way of exposure}


Way of exposure indicates how plants were exposed to NPs and the criteria used for that. This section was also organized into four groups: i) leaf for foliar application of dispersed NP; ii) root includes NP applied in the soil, substrate, sand, river sediments, and hydroponics; iii) seeds for seed treatment-like procedures, and iv) plant tissue.

The most common forms of foliar application consisted in spraying and leaf dipping in NP dispersion. Aquatic plants were considered as leaf exposure.

Root exposure included all forms of contact with NP trough roots.

Seed exposure enconpasses studies that mimic conventional seed tretamented. It included the following processes: soaking, priming and coating with NP. Studies in which seeds were only germinated over media such as filter paper, cotton pads, soil or agar-like, containing NP were not considered as seed treatment. These papers were classed as root exposure. On the other hand, studies in which seeds were soaked, primed or coated with NP, and then germinated in a media containing NP were considered as seed exposure.

A total of 991 articles were consulted and data from 987 were employed to make Figure 4a. The form of exposure in four articles could not be determined.

Tissue exposure includes plant callus, cells, or organs cultivated in vitro conditions with culture medium containing NPs. Articles in which the way exposure was not clear were classified as "Not clear".

\section{Time of exposure}

The time of exposure expresses the time that plants were exposed to NPs. The criteria adopted to organize the data were as follows. Articles that cited the exposure time as "until maturity" were not considered, and those that presented plant exposure to less than 24 hour were considered equal to one day. 
Likewise, some studies gave the approximate exposure time, for example nearly 'two days', in such cases numbers were rounded. When the manuscript informed a time range, the rounded average to the highest value was considered, for example, "5 to 10 days" $=7.5$ days $=$ 8 days. For articles that presented more than one exposure time, all the exposed values were taken into the database.

To build the Figure 4b, concentration reported in $\mathrm{mg} \mathrm{L}^{-1}$, we consulted 788 manuscripts, among which 68 did not inform or it was not clear which was the exposure time. For Figure b, concentration reported in $\mathrm{mg} \mathrm{kg}^{-1}$, we consulted 209 manuscripts and 16 among them did supply or could not find clear information regarding the exposure time.

\section{Concentration of Nanoparticles}

The concentration of nanoparticles was separated into group i) NP dispersed in liquid which concentration could be standardized in units of $\mathrm{mg} \mathrm{L}^{-1}$; group ii) NP dispersed in solid which could be standardized as $\mathrm{mg} \mathrm{kg}^{-1}$. Articles that cited the concentration in other units such as ppm, \%, wt.\%, molarity, $\mathrm{mg} / \mathrm{mL}, \mathrm{mg} / \mathrm{g}$ were converted to $\mathrm{mg} / \mathrm{L}$ or $\mathrm{mg} / \mathrm{kg}$ of NPs. On the other hand, articles that cited concentration as the amount applied per area (mg/hectare, for example) were considered as 'not applicable'.

We consulted 752 articles to produce Figure $4 \mathrm{c} \mathrm{mg} \mathrm{L}{ }^{-1}$, among those 12 articles were considered as 'not applicable'. The considered papers employed 2344 treatments.

We also consulted 210 articles to produce Figure $4 \mathrm{c} \mathrm{mg} \mathrm{kg}-1$ and 7 of them were considered 'not applicable'. The considered papers employed 1175 treatments.

\section{Effects on plants and correlation}


Effect on plants was evaluated only on articles that dispersed NPs in soil, substrate, and sand (194 original articles and a total of 1060 treatments were identified, among those 133 treatments were considered as 'not applicable' ).

The effects were classified as "Beneficial", "Harmful", 'Beneficial \& Harmful', and 'No effect'.

The articles that did not evaluate plant responses as an effect of NP exposure in terms of development and physiology were identified as "Not Applicable", this data was not added to Figure 5a. Instead, it was just reported in the worksheet "Figure 5a- effect". Additionally, we correlated the data of concentration of NPs in soil, species, and soil $\mathrm{pH}$ with the effect individually.

Regarding the effects on enzymes, we avoided reinterpreting the statements made by the authors. For example, an increase of enzymatic activity can either be considered a positive or negative effect depending on the context. We followed the interpretation given by the authors.

Most of the data uncertainty (57\%) was related to incorrect effect evaluation itself, and $43 \%$ was due to errors on the number of treatments evaluated. Particularly, the data from Figure 5a was one of the most difficult of mining. Many studies did not clearly state whether the effect is beneficial, harmful or absent over the treatments, and consequently causing an increasing chances of error occurrence by human evaluation.

Moreover, the effects of NPs on soil microorganisms population were characterized. In the present study such effects were classified as increase, decrease, not change, and increase/decrease. For example, increase in either richness or abundance was considered as "increase". Some papers reported an increase of certain phylum and decrease in another, which reflects a modification in the community structure, in this case the effect was "increase and 
decrease". in which they were classified as "increase", "decrease" or "not change (Figure 5b). For this figure we evaluated 194 articles and 1060 treatments.

\section{Error estimation \& data availability}

Since we went through a large amount of data and considering that the worksheets were filled out manually, human errors occurred during the data mining process. Since writing is also a matter of style, some papers were much clearer than others. In general, the least clear information was related to the type of environment where the experiments were carried out, effects of NP on plants, particularly on enzymatic responses, and imprecise concentration units such as $\%$ and ppm.

Before plotting the data, at least $20 \%$ of the mined data of each worksheet was randomly double-checked the percentage of errors was measured. Then, the incorrect entries were corrected, which decreased the reported error. Each Figure in the manuscript is accompanied by an upper value of error estimation.

Finally, for sake of clarity and expecting that other scientists could reuse the mined data, the worksheets used to plot the Figures are available at Figshare repository ${ }^{20}$ 